\title{
"PCR universal o de amplio espectro": Un aporte a la detección e identificación de bacterias y hongos en la práctica clínica
}

\author{
Helena Poggi M, Ana María G uzmán D, Patricia García C, \\ Marcela Lagos L.
}

\author{
Universal or broad-range \\ polymerase chain reaction $(P C R)$ : \\ $A$ contribution to the detection and \\ identification of bacteria and fungi \\ in clinical practice
}

The use of techniques for the detection of nucleic acids such as the polymerase chain reaction (PCR) has had a major impact on microbiological analysis, playing an important role in the clinical laboratory. Most of the techniques currently used are designed for specific detection of a particular microorganism. However, infectious agents can also be identified even if genus or species are unknown, using universal primers to amplify bacterial or fungal DNA and then identify the species by sequency (universal or wide spectrum PCR). This methodology is applied in cultures that are difficult to identify using phenotypic techniques, and more recently it is also being used directly in clinical samples, where the detection and identification of the infectious agent by traditional techniques is difficult or not possible (Rev Méd Chile 2009; 137: 1122-5).

(Key words: Clinical laboratory techniques: Microbiology; Polymerase chain reaction)

\section{RESUMEN}

El uso de técnicas para la detección de ácidos nucleicos como la reacción en cadena de la polimerasa (PCR) ha tenido un gran impacto en el diagnóstico microbiológico, ocupando un lugar importante en el laboratorio clínico. La mayoría de las técnicas en uso han sido diseñadas para la detección específica de un microorganismo. Sin embargo, también es posible identificar el agente etiológico aunque se desconozca la especie o el género, utilizando partidores universales para amplificar el ADN de bacterias y hongos, y luego secuenciar para identificar la especie (PCR universal o de amplio espectro). Esta metodología se aplica en cultivos difíciles de clasificar por técnicas fenotípicas, pero también se ha comenzado a utilizar directamente en muestras clínicas, en las que la detección e identificación del agente infeccioso por técnicas tradicionales resulta difícil o no es posible. 
DE LA VIDA REAL

Paciente de 32 años consulta en el Servicio de Urgencia por fiebre de hasta $39,5^{\circ} \mathrm{C}$ de una semana de evolución, en el que al examen físico destaca soplo cardiaco. Por sospecha de endocarditis bacteriana se decide su hospitalización y se solicitan exámenes de ingreso, hemocultivos y ecocardiograma. Este último demuestra vegetaciones en la válvula mitral; sin embargo, los hemocultivos resultan repetidamente negativos. Se inicia terapia antibiótica empírica, a pesar de la cual el paciente persiste febril y evoluciona con insuficiencia cardiaca, por lo que se decide reemplazar la válvula. En cirugía de recambio valvular se envía tejido con vegetación a estudio microbiológico tradicional, sin obtener crecimiento bacteriano.

¿Qué otras alternativas existen para identificar el agente infeccioso?

La identificación precisa del agente patógeno en una infección por bacterias u hongos es tarea fundamental del laboratorio microbiológico, ya que permite el manejo apropiado del paciente y la elección de antibióticos. La mayor parte de los microorganismos de interés clínico pueden aislarse e identificarse a bajo costo a través de cultivos microbiológicos convencionales y pruebas basadas en las características fenotípicas del agente patógeno aislado. Sin embargo, en ocasiones los microorganismos pueden ser difíciles de identificar, de aislar, de crecimiento lento o no ser cultivables. Esto se puede deber a características propias de la bacteria o el hongo, o a que el paciente haya recibido tratamiento previo con antibióticos o antifúngicos. Como apoyo al diagnóstico etiológico de infecciones en estas situaciones, se han introducido al laboratorio clínico métodos basados en la detección de ácidos nucleicos de microorganismos, como la $\mathrm{PCR}^{1}$.

Frente a la sospecha clínica de un microorganismo en particular, la detección se realiza en forma dirigida utilizando metodologías que permiten detectar e identificar un agente específico, como por ejemplo la PCR para Mycobacterium tuberculosis complex, Pneumocystis jiroveci, Bordetella pertussis, etc., las que se han incorporado a la rutina de muchos laboratorios y a la práctica clínica. Para casos en que la sospecha es amplia y por lo tanto la búsqueda no es dirigida, se han desarrollado métodos, cuyo diseño permite detectar e identificar potencialmente toda bacteria $\mathrm{u}$ hongo, llamados "PCR universal o de amplio espectro" 2,3 .

\section{¿En qué consiste la PCR universal?}

La PCR universal consta de dos etapas: la amplificación del ADN bacteriano o fúngico de la muestra y la posterior secuenciación del fragmento de PCR para la identificación del microorganismo (Figura 1). Las regiones del genoma que se utilizan deben cumplir con características fundamentales: a) estar presentes en todas las especies bacterianas o fúngicas; b) contener secuencias altamente conservadas a las cuales van dirigidos los partidores; y c) incluir secuencias polimórficas para poder diferenciar distintas especies ${ }^{4}$. Luego de amplificar y secuenciar el fragmento, la secuencia obtenida se compara con aquellas depositadas en bases de datos públicas como Genbank del NCBI (National Center for Biotechnology Information, http://www.ncbi.nlm.nih.gov) o RIDOM (Ribosomal Differentiation of Medical Organisms, www.ridom.de). Para el alineamiento de secuencias están disponibles programas como BLAST (http://www.ncbi.nlm.nih.gov/BLAST) que permiten la comparación de secuencias on line. Aunque aún no hay definiciones claras respecto de los porcentajes de similitud (entre secuencia obtenida y la de referencia) para delimitar la pertenencia a una especie o género, están disponibles hoy guías como las del Clinical and Laboratory Standards Institute $(\mathrm{CLSI})^{5}$, con criterios para la interpretación de los resultados que son de gran ayuda para los laboratorios que realizan estas metodologías.

En bacterias, la identificación de especie a nivel molecular se basa en el análisis del gen que codifica para el ARN ribosomal de la subunidad 16S $\left(16 \mathrm{~S}\right.$ rRNA) ${ }^{6}$. Esta molécula de alrededor de 


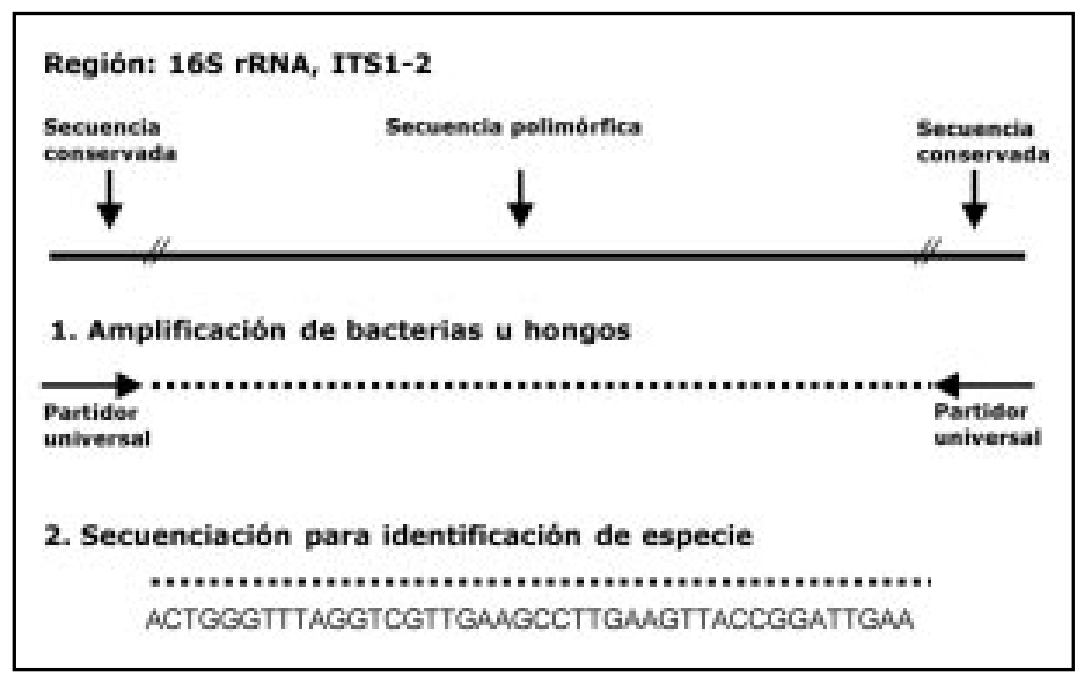

Figura 1. Esquema del PCR universal para bacterias y hongos. A partir de la región del genoma correspondiente: 1) se amplifica un fragmento de PCR utilizando partidores dirigidos a secuencias conservadas en todas las bacterias u hongos (universales) y 2) se secuencian las regiones polimórficas para identificar la especie.

$1.500 \mathrm{pb}$, presente en todas las bacterias, fue la primera en utilizarse para identificación bacteriana y ha sido la más ampliamente utilizada para estudios de filogenia y taxonomía bacteriana, lo que ha contribuido a que existan amplias bases de datos. Generalmente, es suficiente analizar las primeras 500 pb de este gen, ya que es la región más variable, pero en otros casos no es posible resolver a nivel de especie aun secuenciando el gen completo, por lo que se debe recurrir al estudio de otros sitios del genoma ${ }^{7}$. En analogía, para la PCR universal de hongos se utilizan partidores dirigidos a zonas conservadas de los genes que codifican para las subunidades ribosomales 18S, $5.8 \mathrm{~S}$ y 28S. Entre estos genes se encuentran las regiones ITS-1 y 2 (internally transcribed spacer 1 y 2), las cuales son altamente variables y permiten diferenciar entre las distintas especies fúngicas ${ }^{4}$.

¿En cuáles casos se puede utilizar la PCR universal? La identificación de microorganismos por PCR universal a partir de cultivo se ha convertido en una herramienta importante en laboratorios de referencia, sobre todo para identificar microorganismos con características fenotípicas equívocas y también para clasificar bacterias u hongos poco comunes, por lo que se espera que se incorpore cada vez más a la rutina del laboratorio clínico ${ }^{8}$.

Más recientemente, se ha utilizado directamente en muestras clínicas. Existen series amplias publicadas en la literatura en las que se ha demostrado su utilidad diagnóstica como, por ejemplo, en válvulas cardiacas, líquido cefalorraquídeo, tejido óseo y líquido articular? ${ }^{9}$. El uso de esta metodología se restringe al análisis de muestras de sitio estéril, ya que la presencia de más de un agente dificulta la obtención de resultados concluyentes al secuenciar. La posibilidad de analizar muestras por PCR universal adquiere especial importancia cuando se han agotado todas las otras alternativas disponibles para detectar el microorganismo e identificar la especie (cultivo convencional, serología, e incluso métodos moleculares para detección específica).

Estas metodologías, ¿están disponibles para su uso clínico?

La PCR universal está disponible hoy día en nuestro país, tanto para el análisis de muestras obtenidas de cultivo con identificación fenotípica dudosa, como también para muestras clínicas de sitio estéril, en las cuales se sospecha un agente no cultivable. Esto se debe, principalmente, a que 
en los últimos años se han producido avances tecnológicos importantes, lo que ha permitido que metodologías como la secuenciación estén cada vez más al alcance de los laboratorios clínicos. Además, los costos han disminuido en forma importante, por lo que en ocasiones la identificación de especie por secuenciación puede resultar, incluso, más barata y rápida que realizar múltiples pruebas fenotípicas.

La principal dificultad para la implementación de una PCR de amplio espectro, en la que se amplifica potencialmente todo ADN de bacteria u hongo, es el manejo adecuado de posibles contaminaciones que, de producirse, no permitirían llegar a un resultado concluyente. Esto adquiere especial relevancia en el análisis de muestras clínicas directas, en las que la cantidad de ADN presente es habitualmente pequeña, en comparación a un cultivo. Aun en un laboratorio con experiencia en microbiología molecular, la implementación de una PCR de amplio espectro es un desafío y se hace necesario tomar precauciones adicionales a las que se toman en las PCR de detección específica para evitar contaminaciones (toma de muestra bajo condiciones de esterilidad, separación estricta de áreas dentro del laboratorio, uso de reactivos y materiales específicamente

\section{REFERENCIAS}

1. Espy MJ, Uhl JR, Sloan LM, Buckwalter SP, Jones MF, VetTer EA et Al. Real-time PCR in Clinical Microbiology: Applications for Routine Laboratory Testing. Clin Microbiol Rev 2006; 19: 165-256.

2. Harris KA, Hartley JC. Development of broad-range $16 \mathrm{~S}$ rDNA PCR for use in the routine diagnostic clinical microbiology service. J Med Microbiol 2003; 52: 685-91.

3. Vollmer T, Störmer M, Kleesiek K, Dreier J. Evaluation of Novel Broad-Range real-time PCR Assay for Rapid Detection of Human Pathogenic Fungi in Various Clinical Specimens. J Clin Microbiol 2008; 46: 1919-26.

4. PetTI CA. Detection and identification of microorganisms by gene amplification and sequencing. CID 2007; 44: 1108-14.

5. MM18-a CLSI - Interpretive Criteria for Identification of Bacteria and Fungi by DNA Target Sequencing; Approved Guideline. CLSI document, MM18-A 2008. destinados a PCR universal, controles de extracción, etc. $)^{10}$.

\section{Conclusiones}

En la última década, la detección e identificación de especie por PCR universal o de amplio espectro se ha trasladado del ámbito de la investigación al laboratorio clínico, ya que es un aporte importante para el diagnóstico del agente infeccioso, tanto a partir de cultivo como directamente de muestras clínicas. Esta metodología permite identificar microorganismos de una forma más reproducible y exacta que por características fenotípicas, sobre todo en agentes difíciles de identificar o cultivar, contribuyendo a la identificación de patógenos no descritos localmente e, incluso, al descubrimiento de nuevos patógenos. Estas nuevas herramientas no sólo representan un aporte al establecer la etiología de una infección en casos que la microbiología tradicional no lo logra, sino que ayuda al clínico a seleccionar o adecuar el tratamiento antibiótico.

En el caso clínico que se presenta habría sido de utilidad entonces, realizar una PCR universal en el tejido valvular para identificar el agente etiológico y orientar la terapia.

6. Rodicio M, Mendoza MC. Identificación bacteriana mediante secuenciación del ARNr 16S: fundamento, metodología y aplicaciones en microbiología clínica. Enferm Infecc Microbiol Clin 2004; 22: 238-45.

7. Janda JM, Аввотt SL. 16S rRNA Gene Sequencing for Bacterial Identification in the Diagnostic Laboratory: Pluses, Perils, and Pitfalls. J Clin Microbiol 2007; 45: 2761-4.

8. Woo PC, Lau SK, Teng JL, Tse H, Yuen KY. Then and now: use of 16S rDNA gene sequencing for bacterial identification and discovery of novel bacteria in clinical microbiology laboratories. Clin Microbiol Infect 2008; 14: 908-34.

9. Sontakke S, Cadenas MB, Maggi RG, Diniz PP, BreitsCHWERDT EB. Use of broad range 16S rDNA PCR in clinical microbiology. J Microbiol Methods 2009; 76: 217-25.

10. Millar BC, Xu J, Moore JE. Risk Assessment Models and Contamination Management: Implications for BroadRange Ribosomal DNA PCR as a Diagnostic Tool in Medical Bacteriology. J Clin Microbiol 2002; 40: 1575-80. 